\title{
Modelling Tax-Consumption Relationship: An Empirical Evidence from Asia
}

\author{
TAN SHU HUI \& MUHAMMAD ASRAF ABDULLAH* \\ Faculty of Economics and Business, Universiti Malaysia Sarawak, 94300 Kota Samarahan, Sarawak, Malaysia. \\ *Corresponding author: amasraf@unimas.my
}

\begin{abstract}
This study examines the impact of taxation on consumption behaviour by focusing on selected countries from Asia. The study adopts panel fixed effect and random estimators to gauge the influence of tax on consumption expenditures. Findings of the study support negative influence of tax on household consumption. The finding is parallel with the absolute income hypothesis that high volume of tax collected from the public results in falling households' disposable incomes, hence downwardly affecting households' consumption levels. The study's finding implies the importance of carefully observing an appropriate tax policy that suit the country's level of development in order to promote high rates of economic growth and consumption.
\end{abstract}

Keywords: Tax revenue; Fiscal policy; Government revenues; Household consumption; Public Economics

Copyright: This is an open access article distributed under the terms of the CC-BY-NC-SA (Creative Commons Attribution-NonCommercial-ShareAlike 4.0 International License) which permits unrestricted use, distribution, and reproduction in any medium, for non-commercial purposes, provided the original work of the author(s) is properly cited.

\section{INTRODUCTION}

Over the past decades, household consumption expenditure remained the largest contributor to GDP for many countries in Asia. According to the World Bank (2017), household consumption expenditures of most selected Asian countries have contributed to more than 50\% of GDP from 2012 to 2016. There is a high percentage of contribution of consumption to GDP although some of the countries like Japan and Thailand recorded a decreasing trend in household consumption expenditure. According to the World Bank (2018), consumption expenditure forms the largest component of the aggregate demand for some Asian countries. Consumption plays an important role in the economy since it has a significant effect on economic growth of a country (Kim, 2017). Therefore, this study is carried out to further investigate the nexus between tax revenue and households' consumption patterns in the Asian's region.

The significant contribution of consumption expenditure to GDP in Asia has motivated this study to examine the impact of tax on consumption level since most Asian countries rely heavily on income taxes as the main source of government revenue for decades (The World Bank, 2018). According to Keynes (1936), the propensity to consume is a fairly stable function where the aggregate consumption depends on aggregate income of the household. The consumption expenditures of households rise as their income levels increase. Tax may affect the disposable incomes of households and their purchasing power, thus negatively affecting their aggregate consumption level. A lower tax rate increases the disposable income and spending power of consumers, thus stimulating consumption expenditure as consumers have more money to spend and vice versa. With a lower tax rate, consumption expenditure of household would rise, resulting in an increase in the aggregate demand which promotes a higher economic growth and increases social welfare of a country (Pettinger, 2017).

In recent years, the relationship between tax and consumption expenditure had received growing attention among researchers. Some of the studies were highlighted by Ajibola and Segun (2017), Leka (2015), and Eusebio and Franchesca (2013) who suggested a positive impact of tax on households' consumption expenditure. Other group of researchers namely Varlamova and Larionova (2015), Tamasauskiene and Opulskyte (2012), Baker and Kueng (2016), and Kolahi et al. (2016) emphasised on negative relationships between tax and consumption expenditure. These mixed 
results suggested the need to reinvestigate the issue of tax-consumption relationship in order to suggest appropriate policy implication to the policy makers.

Tax is a compulsory contribution to state revenue. It is levied by the government on individual income and organization profits, or added to the cost of some goods, services, and certain activities (Hyman, 2011). Taxes affect both consumers and producers as it has the tendency to change both demands and supplies of goods and services through changes in prices, hence, influencing resource use patterns (Hyman, 2014). Tax affects economic growth via changes in households' consumption behavior (Ebiringa \& Yadirichukwu, 2012; Unegbu \& Irefin, 2011; William \& Benjamin, 2010). Therefore, this study focuses on the impact of tax from consumer's context.

The general idea of investigating the relationship between tax and consumption was based on the absolute income hypothesis. This hypothesis was proposed by Keynes (1936) to identify the relationship between disposable income and consumption in his general theory. Keynes asserted that real consumption is a function of real disposable income that is net income after deducting taxes. Consumption will decrease with the rise in tax that reduces the households' disposable income and vice versa. The simple Keynesian consumption function is written as follows:

$$
C_{t}=\alpha+\beta\left(Y_{d}\right)
$$

Where,

$C_{t}=$ Consumption at the time $t$

$\alpha=$ Autonomous consumption

$\beta=$ Marginal propensity to consume

$Y_{d}=$ Disposable income at time $t$

According to simple Keynesian model in equation 1, marginal propensity to consume (MPC) is the ratio between the change in consumption expenditure and the change in disposable income which is income after taxes paid. It measures the change in consumption expenditure as a result of changes in every unit of disposable income. The MPC is assumed to be positive and constant while the autonomous consumption is expected to be positive and small.

This hypothesis postulates some important characteristics. These characteristics are including non-proportionality where consumption expenditure increases or decreases with the rise or the fall in income. The non-proportional consumption function stated that MPC is smaller than average propensity to consume $(M P C<A P C)$ in the short run due to non-changing autonomous consumption function with income in the short run. However, MPC is equal to APC in the long run. This is because there is a proportional relationship between income and consumption.

The Keynesian consumption function is written as $C=A+B\left(Y^{d}\right)$. Where $\mathrm{C}$ is the consumption expenditure, $A$ represents autonomous spending, $B$ is the marginal propensity to consume, and $Y^{d}$ represents real disposable income. Theoretically, tax has a significant and negative impact on the disposable income of household, thus downwardly affecting household consumption expenditure.

There is a growing body of literature that examine the association between tax and consumption focusing on different regions and countries across the globe over the past decades. Among these literatures are that associated to investigation of relationship between varying taxes types and household consumption in different countries settings namely countries of the OECD including United States, Europe and Asia. Most of the research findings suggest negative impact of different types of taxes on household consumption while others opposed.

Among the strand of research that support positive impact of taxes on consumption are highlighted by Eusebio and Franchesca (2013), Leka (2015) and Ajibola and Segun (2017). The study's findings suggest that tax is one of the factors that influence consumption expenditure of household. In a way, these research suggests that a rise in net tax by one percent will increase the households' consumption expenditures.

Eusebio and Franchesca (2013) conducted a study to investigate the impact of macroeconomic variables on consumption expenditure in the Philippines using quarterly time series data based on OLS and Maximum Likelihood estimation techniques over the period 1947 to 2007. Next, by employing annual time series regression analysis for the period from 1985 to 2013 using sample data from Albania, Leka (2015) extends the study of relationship between tax and consumption. Subsequently, the study by Ajibola and Segun (2017) who applies the OLS regression technique 
on annual economic dataset from Nigeria for the period 1994 to 2014 shows positive influences of value added tax and company income tax on household consumption expenditure. The study's results postulate that an increase in the rates of indirect taxes is associated to the increase in household consumption expenditure.

In contrast to above studies, Romer and Romer (2010), Alm and Ganainy (2012), Tamasauskiene and Opulskyte (2012), Varlamova and Larionova (2015), Strilkova and Siroky (2015), Baker and Kueng (2016), Kolahi et al. (2016), and Bartkus (2017) who apply panel data estimation approach argue negative relationships between tax and consumption expenditure of household. Applying the panel OLS to analyse the sample countries from OECD, Varlamova and Larionova (2015) revealed negative relationship between taxes and household expenditure. Subsequently, by extending the panel estimation to dynamic panel data based on generalized method of moments (GMM) system estimators to different countries set, Alm and Ganainy (2012) and Kolahi et al. (2016) confirm that VAT (value added tax) has a significant negative effect on consumption. An increased VAT would result in a reduction of consumption. Similarly, another study done by Tamasauskiene and Opulskyte (2012) using multiple regression analysis also portrays a negative relationship between indirect taxed and household consumption expenditure.

Another branch of literature leading by Strilkova and Siroky (2015), Baker and Kueng (2016), and Romer and Romer (2010) who employed time series data in their analyses also support a negative effect of tax on consumption. The finding by Strilkova and Siroky (2015) indicates that lower VAT rate would result in a higher net income, hence pushing the consumer expenditures up. The study collects data using questionnaires and adopts analytic-synthetic and comparative methods to analyze the sample data from Czech Republic. Baker and Kueng (2016) and Romer and Romer (2010) observe a strong correlation between household spending and changes in taxes as consumers tend to change their consumption pattern following an increase in tax rate in the United States. Another literature by Bartkus (2017) who applies time series analysis using unit root, VAR and Granger causality also convey a negative consumption impact resulting from high tax rate in Lithuania.

Meanwhile, another strand of literature for instance, Miki (2011), Tochukwu et al. (2015), and Hussain and Malik (2016) confirm mixed results with some literature suggest a positive nexus while others indicate an opposite nexus between the tax and consumption expenditure. In the studies by Hussain and Malik (2016) and Tochukwu et al. (2015) who apply different estimation approaches where the former adopts censored regression model while the later applies OLS estimation technique arrive at similar conclusion of a positive nexus between tax and household consumption expenditure on non-durable goods and negative impact of the tax and household consumption expenditure on durable goods.

Miki (2011) who investigates the effect of the VAT rate on aggregate consumption in 14 developing countries using fixed and random effect estimation method supports similar mixed result. The sample data for the study are separated into two groups, one group consists of data before implementation and the other consists of data after implementation of VAT. The finding for first group of data implies a positive tax-aggregate consumption relationship. Next finding for second group indicates a negative effect of VAT reduction on aggregate consumption.

The above review of tax impact on consumption highlighted mixed results where the tax and consumption expenditure may have a positive, a negative or both negative and positive nexus across different settings of studies. These inconsistent findings signal the need for re-estimation of the relationship between tax and consumption by focusing on different context of study.

This paper is dissected into five sections. Section one discusses the motivation of the study by emphasizing on the significance contribution of consumption expenditure on GDP. The section also discusses how tax influences disposable incomes which finally changes the consumption expenditure of households. In addition, this section explicates the conventional theory of consumption based on Keynes's (1936) view. In discussing the consumption theory, review of selected past literatures is carried out in order to explain why tax and consumption relationship merits further investigation. Section two explores the data and methodology that are applied in the study's analysis. The results and discussion of the study are presented in section four. Lastly, section five provides the conclusion of the study. 


\section{MATERIALS \& METHODS}

This study uses panel data that consists a sample of seven countries for five years spanning between 2012 and 2016. The study period is chosen to avoid fluctuations in economic data due economic crisis. The study employs annual data with a total of 35 observations. The independent variable of our interest for this study is tax. Tax variable in our context of study comprises of total tax revenues including income tax, consumption tax and indirect tax revenues. It can affect the distribution of income and wealth, mode of consumption as well as the pattern of production. Tax data in this study is proxy by total tax revenue collected by the government for a particular year. In this study, tax is taken as the percentage of GDP.

Meanwhile, GDP per capita and gross savings are served as the control variables as commonly found in other literature regarding the relationship between tax and consumption. GDP per capita is an index that measured the degree of total economic output relative to the population of a nation in a particular year. It is calculated by dividing GDP at the current market prices with the number of population of a country before adjusting for inflation (The United Nations, 2017a). GDP per capita is a common indicator of the economic well-being of a citizen. Theoretically, the nexus between GDP per capita and household consumption expenditure should be positive. A rise in GDP per capita results in an increase of purchasing power of household.

Next, gross savings is an indicator that measures the level of resources or funds that are available for investment in capital asset (The United Nations, 2017b). Savings could contribute to sustainable future economic growth by increasing the amount of capital available for investment. Gross savings in this context of study are calculated by gross disposable income less consumption. Saving has a negative relationship with consumption. On the other hand, household consumption expenditure is the dependent variable for this study.

In this study, consumption is proxied by household consumption expenditure since it consists of the spending on goods and services that are incurred by households. Data of household consumption expenditure in this study is measured by taking the ratio of consumption to GDP. All the raw data for the variables are standardized in USD before conversion into percentage or ratio. All the data for this study are procured from the World Bank.

This study's analysis adopts panel random effect estimator based the studies by Burge and Rogers (2011) and Miki (2011) with arguments that the models suit short time periods (small $T$ ) and more countries (large $N$ ). According to Williams (2018), the random effects estimator is more efficient than the pooled OLS because the errors are classical. Nevertheless, it is more efficient compared with fixed effect estimator as it does not use a large number of dummy variable and loss of the degrees of freedom can be avoided if the $\mu_{i}$ can be assumed random. Furthermore, panel data is applied in this study since it provides rich data with both time series and cross section dimensions that account for heterogeneity effect of countries. In order to recognize the best panel estimator for analysis of the study, two tests have been applied to identify suitability of pooled OLS, random effect and fixed effect models namely Breusch-Pagan Lagrange Multiplier (LM) test and the Hausman test. The relationship between tax and household consumption expenditure is modeled as follows:

$$
H C E_{i t}=\beta_{0}-\beta_{1}\left(T_{i t}\right)-\beta_{2} \log \left(G D P P C_{i t}\right)-\beta_{3}\left(G S_{i t}\right)+\varepsilon_{i t}
$$

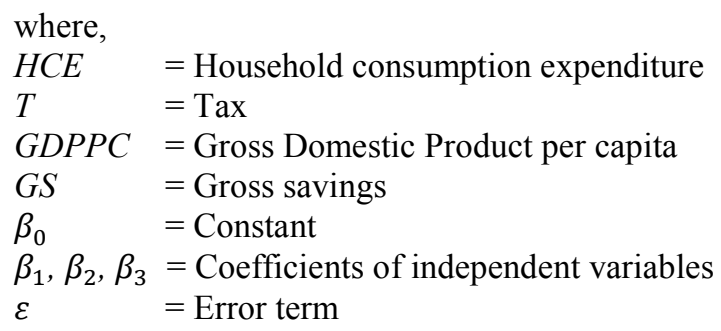

The expected impact of tax on household consumption expenditure is negative according to the Keynesian absolute income hypothesis. Nonetheless, there might be a positive impact of tax on consumption if the types of consumption expenditure are different. The consumption expenditure of household is separated into three broad categories which are expenditures for durable goods, non-durable goods, and services. The tax might reduce the consumption of durable good as durable goods are defined as the goods those whose expected lifetime is more than three years. Meanwhile, 
there are positive nexus between the tax and household consumption expenditure on non-durable goods as non-durable goods are something that can be expected to last for a substantial time period (Hussain \& Malik, 2016; and Tochukwu et al., 2015). Two economics variables namely GDP per capita and savings which have incredible influence on consumption according to theory are introduced to ensure correct specification of the model. GDP per capita should have a negative association with consumption because GDP per capita represents household's income. In other word, it means that an increase in GDP per capita would results in rising household income. The increase in household income would suggest more purchasing power for households, thus raising the household consumption expenditure. On the other hand, the relationship between gross savings and household consumption expenditure is anticipated to be negative. Savings is defined by the difference between a person's consumption expenditure and disposable income. Savings are expected to reduce as the consumption increase with the assumption that income is constant in the short run.

\section{RESULTS AND DISCUSSION}

The static panel data regression requires two basic tests to test for suitability between pooled OLS and random effect and fixed effect models. This econometric requirement is satisfied by conducting the Breusch-Pagan LM test. The result of the Breusch-Pagan LM test is depicted in Table 1. The probability statistics obtained from the test is 0.0038 , which is smaller than significance level of $1 \%$ or 0.01 . Hence, we have enough statistical evidence to reject the null hypothesis at $1 \%$ significant level. We conclude the presence of individual specific effect in the model. In other words, the random effect model is more appropriate than the pooled OLS model. This is because the individually specific effects are completely ignored in the pooled OLS model since it is a simple OLS technique of panel data.

Table 1: Result of Breusch-Pagan Lagrangian Multiplier Test.

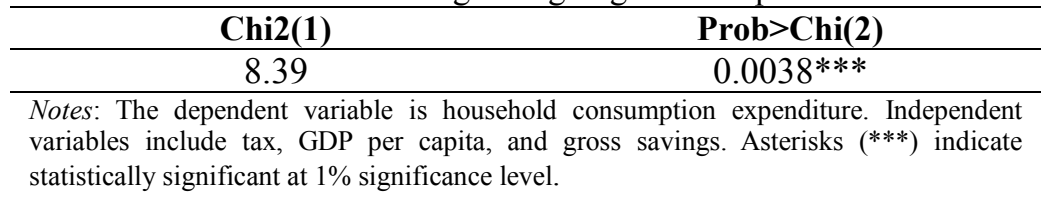

Next, to treat for country specific effects we proceed with the validation of suitability of fixed effect and random effect models to be used for estimating tax impact on consumption. The validation of correct model is done by employing the Hausman test to test for suitability between random effect and fixed effect estimators. The result of the Hausman test is reported in Table 2. As indicated in the results from Table 2, the Hausman value which is given by the Chi Square statistics is 5 . The small Hausman value couple with the large probability value of 0.1719 suggests that we accept the null hypothesis which indicates no correlation between country specific effect and the independent variables. Therefore, we conclude that the random effect is consistent and efficient. In other words, the random effect model is more appropriate than the fixed effects model to estimate the impact of tax on consumption in this study's context. In this study, the fixed effect model has too many parameters, thus results in an enormous loss of degree of freedom. Hence, the individual effects are categorized as random. Besides, random effects model allows for modelling the heterogeneity across units since there are different individual effects in this study but fixed effect model only makes an assumption of homogeneity. Therefore, the random effect model is more appropriate than the fixed effects model in this study.

Table 2: Result of Hausman Test

\begin{tabular}{ccc}
\hline Test Summary & Chi-Square Statistics & Probability \\
\hline Cross-section random & 5.00 & 0.1719 \\
\hline $\begin{array}{l}\text { Notes: } \text { The dependent variable is household consumption expenditure. Independent variables include tax, } \\
\text { GDP per capita, and gross savings. }\end{array}$
\end{tabular}

The impact of tax on household consumption expenditure in selected Asian countries based on the random effect model analysis is demonstrated in Table 3. The results indicate that tax is statistically significant at $1 \%$ significance level since the p-value of tax is 0.004 which is less than 0.01 . Furthermore, the t-statistic value is sufficiently high at 
2.87 which suggests that the tax has a highly significant and negative influence on consumption. This finding is parallel to findings of Romer and Romer (2010), Burge and Rogers (2011), Alm and Ganainy (2012), Bartkus (2017), Varlamova and Larionova (2015), Leka (2015), Strilkova and Siroky (2015), Baker and Kueng (2016), and Kolahi et al. (2016), who propose a negative impact of tax on the household consumption expenditure. The study's finding is in line with absolute income hypothesis's proposition that an increase in tax results in a reduction of income and household consumption expenditure.

Result of control variable, GDP per capita is statistically significant at $10 \%$ significance level with the p-value of 0.053 and moderate t-statistic value of 1.93. This values indicate that GDP per capita has a moderately significant influence on the household consumption expenditure. Nonetheless, the sign of the GDP per capita was negative which is in line with our prior expectation of negative relationship between GDP per capita and consumption. This finding is support by Leka (2015). The increase in the rate of national savings for Asian country results in a decline in the household consumption expenditure despite an increase in GDP per capita.

As for savings variable, the p-value is 0.000 which is less than 0.01 coupled with a strong t-statistic value of 16.46 implies a significant and negative impact of saving on household consumption expenditure. This study's finding is supported by Leka (2015) that a reduction in gross savings results in an increase in household consumption expenditure.

Table 3: Random Effect Model Result

\begin{tabular}{cccc}
\hline Variables & Coefficient & Standard Error & T-statistic \\
\hline T & $-0.7652^{* * *}$ & 0.2663 & -2.87 \\
LGDPPC & $-1.0290^{*}$ & 0.5329 & -1.93 \\
GS & $-0.7911^{* * *}$ & 0.0481 & -16.46 \\
\hline
\end{tabular}

Notes: The dependent variable is household consumption expenditure. Independent variables include tax, GDP per capita, and gross savings. Asterisks $(* * *, *)$ indicate statistically significant at $1 \%$ and $10 \%$ significance level.

\section{CONCLUSION}

This research explores the impact of tax on household consumption expenditure in selected Asian countries. A data set consists of selected seven countries in Asia namely Malaysia, Singapore, Indonesia, Thailand, Japan, Bhutan, and South Korea covering the period 2012 to 2016 is employed in analyzing the tax-consumption relationship. The data set is analysed using panel random effect model. The findings from this study postulates a negative influence of tax on household consumption expenditure. This finding is in agreement with the absolute income hypothesis that a high tax rate results in falling income and consumption levels. In addition, there is a negative impact of GDP per capita and gross savings on household consumption expenditure in selected Asian countries.

A high rate of tax negatively affects the household consumption expenditure through falling disposable income. The study's result suggests that policy makers should implement a suitable tax system if the country would like to foresee a high economic growth in the future as reasonable tax rate would encourage consumer spending. This objective can be accomplished through a favourable fiscal policy which encourage positive growth of business and consumption. There is a need for the policy makers to review existing fiscal policy that encourage business activities and consumption whilst at the same time maintaining sustainable public revenues to implement government projects and policies.

The government may identify other sources of revenues if tax rates were to reduce. Another alternative to ensure sufficient public revenues is to practice prudent spending and prioritizing projects that have the potential to uplift the rate of economic growth of a country. These practices would ensure sustainability of the country's debt.

\section{ACKNOWLEDGEMENTS}

Constructive comments on this paper by the reviewers are gratefully acknowledged. 


\section{REFERENCES}

Alm, J., \& Ganainy, A. E. (2012). Value-added taxation and consumption. International Tax and Public Finance, 20, $105-128$.

Ajibola, J. O., \& Segun, O. P. (2017). Taxation and its influence on Household consumption: The Nigerian experience. International Journal of Economics and Business Management, 3(2), 108-128.

Bartkus, A. (2017). The impact of taxes on the consumption to income ratio. Ekonomika, 96(2), 7-26.

Baker, S, R., \& Kueng, L. (2016). Shopping for lower sales tax rates (NBER Paper No. 23665).

Burge, G., \& Rogers, C. (2011). Local option sales taxes and consumer spending patterns: fiscal interdependence under multi-tiered local taxation. Journal Regional Science and Urban Economics, 41, 46-58.

Ebiringa, O, T., \& Yadirichukwu, E. (2012). Analysis of tax formation and impact on economic growth in Nigeria. International Journal of Accounting and Finance Reporting, 2(2), 367-385.

Eusebio \& Franchesca, N. M. (2013). A regression analysis on the relationship of final consumption expenditure (US Dollars) with GDP per capita, Gross savings, and net taxes on products (1978-2010). Retrieved from https://www.academia.edu/4428396/A_Regression_Analysis_on_the_Relationship_of_Final_Consumption_E xpenditure_US_Dollars_with_GDP_per_Capita_Gross_Savings_and_Net_Taxes_on_Products_1978-2010_

Hussain, S. M., \& Malik, S. (2016). Asymmetric effects of exogenous tax changes. Journal of Economic Dynamics \& Control, 69, 268-300.

Hyman, D, N. (2011). Public Finance: A contemporary application of theory to policy. Tenth edition. USA: Cengage Learning.

Hyman, D, N. (2014). Public Finance: A contemporary application of theory to policy. Eleventh edition. USA: Cengage Learning.

Keynes, J. M. (1936). The general theory of employment, interest and money. New York: Harcourt, Brace.

Kim, H. (2017). The effect of consumption on economic growth in Asia. Journal of Global Economics, 5(3).

Kolahi, S. H. G., Noor, Z. B. M., \& Kashmari, A. (2016). Effects of value add tax on consumption in developing countries. Applied Economics and Finance. 3(2), 186-193.

Leka, R. (2015). Final consumption expenditure in Albania. Retrieved from http://fdut.edu.al/wp-content/uploads/ 2015/11/Rovena-Leka-relationship-of-final-cons.expenditure-with-GDP-per-capita-gross-savings-and-nettaxes-on-product.1985-2013.pdf

Miki, B. (2011). The effect of the VAT rate change on aggregate consumption and economic growth. Columbia University, Centre of Japanese Economy and Business (Paper No. 297). Working Paper Series

Pettinger, T. (2017). The effect of tax cuts. Retrieved from https://www.economicshelp.org/blog/13566/economics/ the-effect-of-tax-cuts/

Romer, C. D., \& Romer, D. H. (2010). The macroeconomic effects of tax changes: Estimates based on a new measure of fiscal shocks. The American Economic Review, 100, 763-801.

Strilkova, R., \& Siroky, J. (2015). Changes in the VAT burden on expenses of selected households in the Czech Republic. Law and Economics Review, 6(3), 189-202.

Tamasauskience, Z., \& Opulskyte, R. (2012). Assessment of impacts of changes in indirect taxes on macroeconomic indicators of Lithuania in context of other EU member States. Social Research, 2(27), 5-18.

The United Nations (2017a). Gross Domestic Product per capita. Retrieved from http://www.un.org/esa/sustdev/ natlinfo/ indicators/methodology_sheets/econ_development/gdp_percapita.pdf

The United Nations (2017b). Gross Savings. Retrieved from http://www.un.org/esa/sustdev/natlinfo/indicators/ methodologysheets/econdevelopment/grosssaving.pdf

The World Bank (2017). World Development Indicators. Retrieved from http://databank.worldbank.org/data/reports. aspx? source $=2 \&$ country

The World Bank (2018). World Development indicators. Retrieved from http://databank.worldbank.org/data/source/ world-development-indicators/preview/on

Tochukwu, O. R., Jerry, K., \& Titus, O. A. (2015). Value added tax and consumption expenditure behaviour of households in Nigeria: An empirical investigation. International Review of Social Sciences, 3(6), 236-248.

Unegbu, A. O. \& Irefin, D. (2011). Impact of VAT on economic development of emerging nations. Journal of Economics and International finance, 3(8), 492-503.

Varlamova, J., \& Larionova, N. (2015). Macroeconomic and demographic determinants of household expenditures in OECD countries. Procedia Economics and Finance, 24, 727 - 733.

William, G. G. \& Benjamin, H. H. (2010). A value-added tax for the United States: Part of the solution. Retrieved from https://www.brookings.edu/research/a-value-added-tax-for-the-united-states-part-of-the-solution/

Williams, R. (2018). Panel Data 4: Fixed effects VS random effects models. Retrieved from https://www3.nd.edu/ $\sim$ rwilliam/stats3/panel04-fixedvsrandom.pdf 